\title{
Design of direct solar PV driven air conditioner
}

\author{
Bin-Juine Huang a, " , Tung-Fu Hou ${ }^{\text {a }}$, Po-Chien Hsu ${ }^{\text {a }}$, Tse-Han Lin ${ }^{a}$, Yan-Tze Chen ${ }^{a}$, \\ Chi-Wen Chen ${ }^{\mathrm{a}}$, Kang Li ${ }^{\mathrm{a}}, \mathrm{K} . \mathrm{Y}$. Lee ${ }^{\mathrm{b}}$ \\ a Department of Mechanical Engineering, National Taiwan University, Taipei, Taiwan \\ ${ }^{\mathrm{b}}$ Department of Engineering Science and Ocean Engineering, National Taiwan University, Taipei, Taiwan
}

\section{A R T I C L E I N F O}

\section{Article history:}

Received 17 July 2015

Received in revised form 31 October 2015

Accepted 7 November 2015

Available online $\mathrm{xxx}$

\section{Keywords:}

Solar cooling

Solar air conditioning

Solar PV cooling

\begin{abstract}
A B S T R A C T
Solar air conditioning system directly driven by stand-alone solar PV is studied. The air conditioning system will suffer from loss of power if the solar PV power generation is not high enough. It requires a proper system design to match the power consumption of air conditioning system with a proper PV size. Six solar air conditioners with different sizes of PV panel and air conditioners were built and tested outdoors to experimentally investigate the running probabilities of air conditioning at various solar irradiations. It is shown that the instantaneous operation probability $(\mathrm{OPB})$ and the runtime fraction $\left(R_{F}\right)$ of the air conditioner are mainly affected by the design parameter $r_{p L}$ (ratio of maximum PV power to load power). The measured $\mathrm{OPB}$ is found to be greater than 0.98 at instantaneous solar irradiation $I_{T}>600 \mathrm{~W} \mathrm{~m}^{-2}$ if $r_{p L}>1.71$. $R_{F}$ approaches 1.0 (the air conditioner is run in $100 \%$ with solar power) at daily-total solar radiation higher than $13 \mathrm{MJ} \mathrm{m}^{-2}$ day $^{-1}$, if $r_{p L}>3$.
\end{abstract}

(c) 2015 Elsevier Ltd. All rights reserved.

\section{Introduction}

The cooling load and the energy consumption of air conditioning system in buildings or vehicles are in phase with solar radiation intensity. Solar cooling is thus promising. Many researchers developed solar cooling technology using absorption or adsorption chiller [2,5]; or ejector cooling [9,11] driven by solar thermal energy. Collector used to drive absorption, adsorption, or ejector chiller requires high energy conversion efficiency at high temperature. Usually, vacuum-tube or parabolic-trough collector is used. The cost of collector as well as heat-driven chiller is high and makes the solar cooling not economical.

Recently, many researches study solar cooling using vaporcompression cooler driven by solar PV system since solar PV system cost falls down very fast. Hartmann et al. [4] compared theoretically solar thermal and photovoltaic cooling for a small office building in Freiburg and Madrid and found that the grid-tied PV system has lower cost of primary energy savings. Similar result is obtained by Ref. [16]. Both [4] and [16] assumed that the PV system used in solar cooling is grid-tied type which does not have energy storage (battery). In these solar cooling systems, the power grid will supply electricity for cooling when solar energy is not available.

\footnotetext{
* Corresponding author.

E-mail address: bjhuang@seed.net.tw (B.-J. Huang).
}

In off-grid applications, solar air conditioner needs to be powered by stand-alone PV system. The design of stand-alone solar cooling system is complicated in view of possible loss of power during low solar radiation periods. A typical example is solar refrigerator. The electricity is produced by photovoltaic panels to drive refrigerator based on vapor compression cycle through battery, charge controller $[3,13,17,18]$ and inverter $[14,15]$.

Axaopoulos and Theodoridis [1] designed a solar photovoltaic powered ice-maker which operates without the use of batteries and may be used in truly autonomous applications in remote areas. The refrigerator is made of four compressors. The operation of the compressors by the PV panels is ensured by the use of a controller, which provides startup, maximum power tracking and power management for the four compressors of the system.

Solar air conditioner is different from solar refrigerator in cooling capacity and load pattern. The refrigerator is always wellinsulated and the cooling load may be increased only when it is suddenly or frequently opened. The effect of thermal mass plays a significant role in stabilizing the refrigerator temperature. In addition, the cooling power is usually small for refrigerator.

For air conditioner, the cooling load is usually large, in several $\mathrm{kW}$, and may vary with solar radiation intensity and outside air temperature. Air filtration or people moving to or from the cooling space also affect the cooling load. Besides, solar radiation may fluctuate. All of these make the design of solar air cooling system 
much more complicated.

Huang et al. [12] developed a stand-alone solar air conditioner driven directly by solar PV. An air conditioner with $200 \mathrm{~W}$ ac power was driven directly by $430 \mathrm{Wp}$ solar PV module. No grid power is connected. In order to stabilize compressor operation and reduce battery cost, a small $24 \mathrm{~V} / 12$ Ah battery was used. An inverter is used to convert PV power into ac power to drive the air conditioner. The battery can supply power for less than $1 \mathrm{~h}$ during low solar radiation periods. Hence, the cooling system may suffer from loss of power. In the present study, six solar air conditioners are designed and tested. The field test results are analyzed to study the effect of design parameters on the system performance.

\section{Experimental setup}

\subsection{Experiment design}

The power supply of air conditioning system is from a standalone solar PV system. It requires a steady power input to compressor for smooth operation under variable solar radiation. A small battery is thus used, called buffer battery. It acts as a buffer to stabilize the compressor operation. A capacitor is connected to the battery in order to suppress the surge power at compressor startup. A microprocessor-based controller with measurements of charge/ discharge current, battery voltage, solar irradiation etc. [7] is used to control the battery charge/discharge and data recording. The schematic diagram is shown in Fig. 1.

The present system did not use MPPT (maximum-power-point tracking control) for maximum power tracking of PV module. Instead, the PV system design is based on nMPPO (near maximumpower-point operation) [6] which matches the performance of solar PV modules with the battery voltage. This avoids the energy loss of MPPT and reduces the cost as well as keeping high reliability.

The air conditioner is used to supply cooling load of a lowenergy house (ZEH-2, Fig. 2) which is used as a meeting room for 12 persons. The inside space of the low-energy house is $7.4 \mathrm{~m}$ long, $3.8 \mathrm{~m}$ wide, $3 \mathrm{~m}$ high with floor area $28 \mathrm{~m}^{2}$. Several passive designs are used in the construction of low-energy house to reduce heat penetration, including interior wall insulation using $10 \mathrm{~mm}$ thick vacuum-insulation panel laminated with $25 \mathrm{~mm}$ fiber material, outer-wall ventilated sun shades, and low-E window with plastic frame $[8,10]$. The overall $\mathrm{U}$-value is $0.22 \mathrm{Wm}^{-2} \mathrm{~K}^{-1}$. The total cooling load of the house is estimated $2,200 \mathrm{~W}$ in summer.

\subsection{Definition of design parameter and performance characteristics of solar air conditioner}

The air conditioning system will suffer from loss of power if the solar PV power generation is not high enough at low solar radiation.

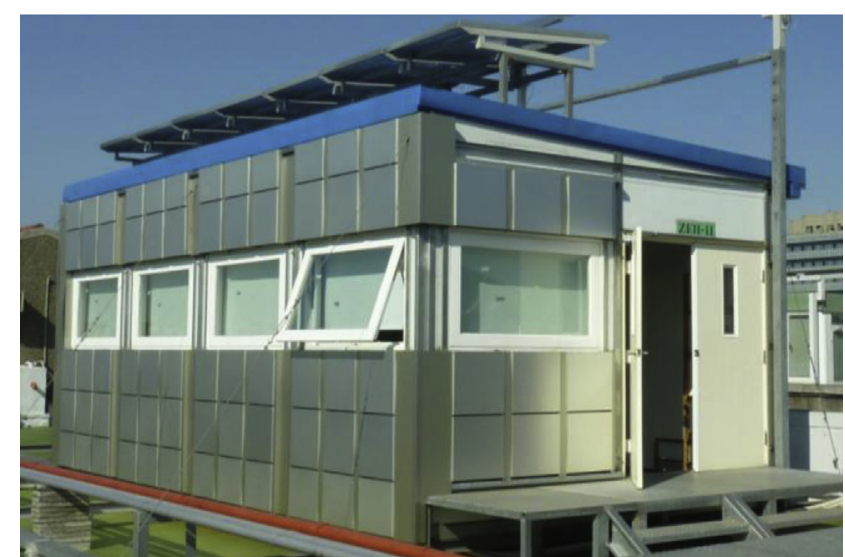

Fig. 2. Low-energy house (ZEH-2).

The instantaneous performance of solar air conditioner can be characterized by the operation probability $(O P B)$ defined in eq. (1) [11]. $O P B$ is defined as the ratio of total running time of the air conditioner to total occurrence time of solar irradiation at specific intensity $I_{T} \pm \triangle I_{T}$ where $\triangle I_{T}$ is the radiation increment chosen as $50 \mathrm{Wm}^{-2}$. OPB is used to characterize the running probability of air conditioner at given solar irradiation $I_{T}$.

$\mathrm{OPB}=\frac{\sum_{j} \Delta t_{\text {on }, j}}{\Delta t_{l_{T}}}$

Another performance index called "runtime fraction" $\left(R_{F}\right)$ defined as the ratio of the total running time $t_{O N}$ of air conditioner to the total service time $t_{\text {total }}$ (taken $8 \mathrm{~h}$ ), eq. (2), can be used to characterize the daily performance [11].

$R_{F}=\frac{t_{O N}}{t_{\text {total }}}$

$R_{F}$ is used to characterize the daily overall performance of solar air conditioner at daily-total solar irradiation $H_{T}$. Actually, $1-R_{F}$ is the time fraction of power loss.

Two system design parameters, $r_{p L}$ and $t_{b p}$, can be used to correlate the PV power generation, load power, and battery storage with OPB and $R_{F}[11,12]$.

$r_{p L}=\frac{W_{p v}}{W_{L}}$

and

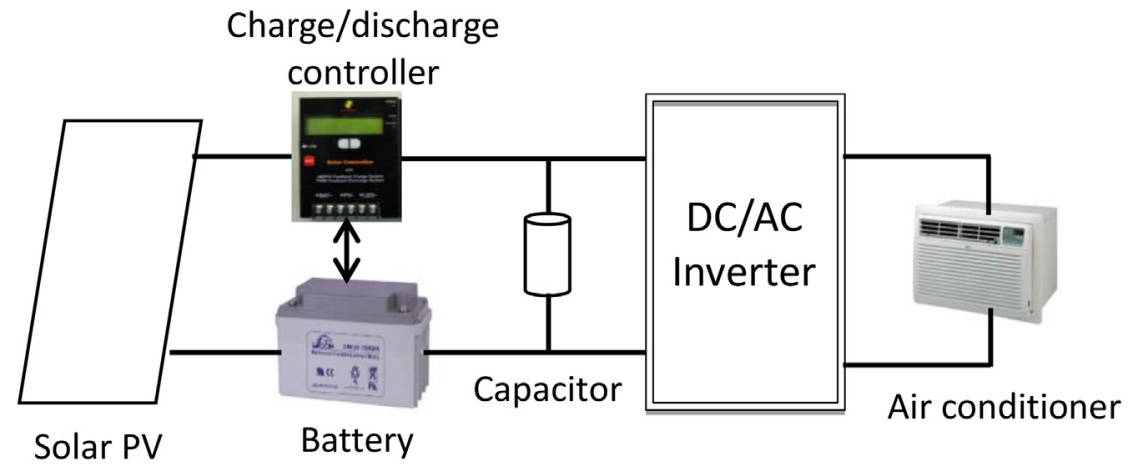

Fig. 1. Schematic diagram of solar air conditioning system. 
Table 1

System specifications of six solar air conditioners.

\begin{tabular}{|c|c|c|c|c|c|c|c|c|c|c|c|}
\hline \multirow[t]{2}{*}{ System } & \multirow[t]{2}{*}{$\begin{array}{l}\text { Compressor } \\
\text { or AC Model }\end{array}$} & \multirow[t]{2}{*}{$\begin{array}{l}\text { PV installed } \\
W_{p v}\left(W_{\mathrm{p}}\right)\end{array}$} & \multirow[t]{2}{*}{$\begin{array}{l}\text { Load power } \\
W_{L}(\mathrm{~W})\end{array}$} & \multicolumn{3}{|c|}{$\begin{array}{l}\text { Battery } \\
\text { installed }\end{array}$} & \multirow[t]{2}{*}{$\begin{array}{l}\text { DOD of } \\
\text { battery (\%) }\end{array}$} & \multirow[t]{2}{*}{$\begin{array}{l}\text { Battery energy } \\
\text { storage } E_{\text {bat }}(\mathrm{Wh})\end{array}$} & \multirow[t]{2}{*}{$r_{p L}=W_{p v} / W_{L}$} & \multirow[t]{2}{*}{$t_{b p}=E_{b a t} / W_{p v}(h)$} & \multirow[t]{2}{*}{$t_{b L}=E_{b a t} / W_{L}(h)$} \\
\hline & & & & Type & $\mathrm{V}$ & Ah & & & & & \\
\hline A1 & Matsushita 2TS023S3B & 430 & 200 & LA & 24 & 12 & 70 & 202 & 2.15 & 0.47 & 1.01 \\
\hline A2 & Matsushita 2TS023S3B & 430 & 200 & LA & 24 & 26 & 70 & 437 & 2.15 & 1.02 & 2.18 \\
\hline B1 & Danfoss FF10GX & 460 & 350 & LFP & 24 & 30 & 70 & 504 & 1.31 & 1.10 & 1.44 \\
\hline B2 & Danfoss FF10GX & 600 & 350 & LFP & 24 & 30 & 70 & 504 & 1.71 & 0.84 & 1.44 \\
\hline B3 & Danfoss FF10GX & 900 & 300 & LFP & 24 & 30 & 70 & 504 & 3.00 & 0.56 & 1.68 \\
\hline $\mathrm{C}$ & Hitachi RAS-22NF & 1380 & 650 & LFP & 24 & 30 & 80 & 576 & 2.12 & 0.42 & 0.89 \\
\hline
\end{tabular}

$t_{b p}=\frac{E_{b a t}}{W_{p v}}$

where $E_{b a t}$ is the usable energy storage of battery (Wh) (= $\left.D O D \times E_{\text {bat } 0}\right) ; D O D$ is the depth of discharge of battery; $E_{\text {bato }}$ is the rated capacity of battery $(\mathrm{Wh}) ; W_{p v}$ is the rated PV maximum power generation; $W_{L}$ is the power input to air conditioner $(\mathrm{W})$.

$t_{b p}$ can be interpreted as the time to fully charge the battery at maximum PV power generation. The PV system with a higher $t_{b p}$ needs a longer time to charge the battery, due to a smaller PV panel installed or a larger battery used.

$r_{p L}$ is the ratio of maximum PV power generation to load power. The PV system with $r_{p L}>1.0$ means that the maximum PV power generation is higher than the load power.

A design parameter $t_{b l}$, eq. (5), is further defined in the present study to represent the maximum service time of battery:

$t_{b L}=\frac{E_{b a t}}{W_{L}}=r_{p L} t_{b p}$

The present field test results are then analyzed to study the effect of system design parameters on $O P B$ and $R_{F}$.

\subsection{Solar air conditioners built for field test}

In order to study the effect of design parameters on $O P B$ and $R_{F}$, six solar air conditioners were designed and built. See Table 1 for detailed specifications. The air conditioners are installed in the lowenergy house (ZEH-2) to supply part of the total cooling load.
Two kinds of batteries, lead-acid (LA) and lithium-ironphosphate (LFP), are used. System A1 and A2 use the same air conditioner but are tested with different sizes of battery. B1, B2 and B3 use the same air conditioner but are tested with different PV sizes and different cooling load power.

The microprocessor-based charge/discharge controller also provides time delay control ( $2 \mathrm{~min}$ ) for System A1, A2, B1, B2, B3 to restart the compressor after stop. The air conditioner used in System $C$ is split inverter-type and does not need time-delay control for restart of compressor. The depth of discharge (DOD) is controlled by setting high and low voltage of battery, $28.3 \mathrm{~V}$ and 23.8 V for LFP battery (System B1, B2, B3), $28.8 \mathrm{~V}$ and $22.8 \mathrm{~V}$ for LA battery (System A1, A2), 29.3 V and 23.8 V for LFP battery (System C). The test results are recorded by imbedded recorder inside the charge/discharge controller.

\section{Test results}

The field test of six systems was carried out continuously. The test results are analyzed in terms of instantaneous performance and daily-total performance statistics. The instantaneous performance at different weather patterns are examined to show the detailed performance, including power consumption of air conditioner, PV power generation, charge/discharge of buffer battery etc. The daily-total performance statistics is used to analyze the overall performance of the solar air conditioner, including $O P B$ and $R_{F}$, which can be utilized in the design of solar air conditioning systems.

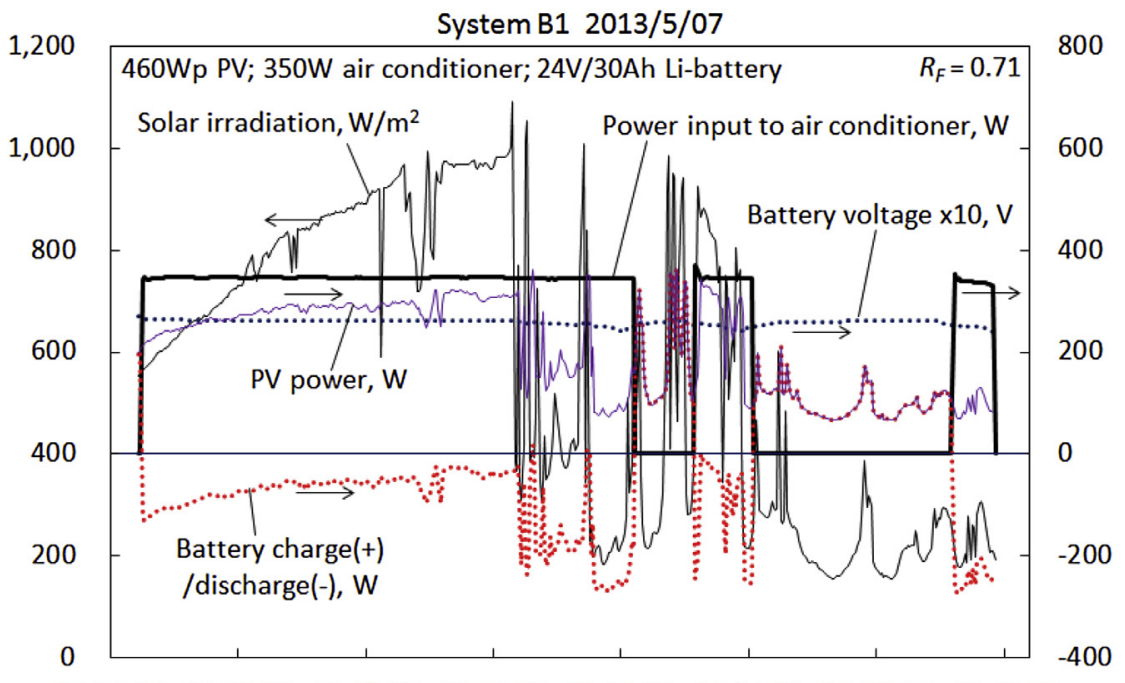

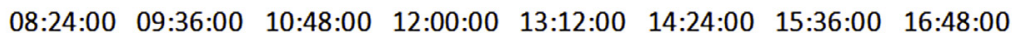

Fig. 3. Instantaneous operation of System B1 $\left(r_{p L}=1.31\right)$. 


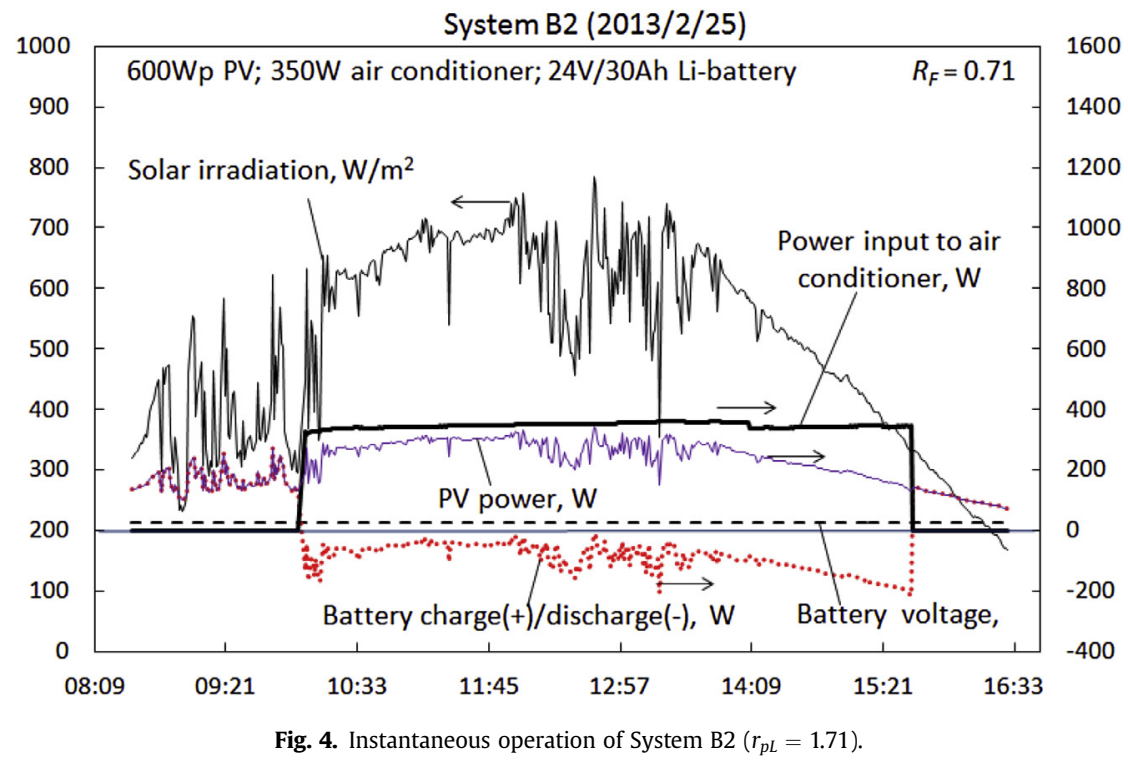

\subsection{Instantaneous performance}

Fig. 3 shows the instantaneous performance of System B1 at partly sunny condition. It is seen that the solar PV $(460 \mathrm{Wp})$ generates power always lower than the load power $(350 \mathrm{~W})$. The battery charge/discharge curve shows that, in the morning when solar radiation is high, the buffer battery provides part of load power (battery discharge), in addition to solar PV power, to drive the air conditioner.

Fig. 3 show that from $12: 12$ to $13: 20$ (68 $\mathrm{min}$ ) and 16:20 to $16: 43$ (23 $\mathrm{min}$ ), both under low solar radiation, battery discharge provides important part of load power. The system loses power when the battery is fully discharged. The load power is lost from 13:20 to 13:54 while the battery still continued charging until fully charged and the air conditioner is restarted. The runtime fraction $R_{F}$, defined in eq. (2), of System B1 tested on May 7, 2013, is 0.71. That is, the air conditioner is run with solar power for $71 \%$ of total running time (8 h).

Fig. 4 shows the performance of System B2 on clear weather. It is seen that the solar PV $(600 \mathrm{Wp})$ generates power about the same as the load power ( $350 \mathrm{~W}$ ) at high solar radiation periods.

The battery charge/discharge curve shows that, in early morning, the battery voltage is low and the solar PV power is not high enough to drive air conditioner. The battery continues charging until fully-charged and the air conditioner is started at 10:05. After then, the solar PV power is very close to load power. The battery provides part of load power for about $5.5 \mathrm{~h}$ until 15:38 without power shutdown of air conditioner.

The runtime fraction $R_{F}$ of System B2 tested on Feb 25, 2013, is 0.71 . That is, the air conditioner is run with solar power for $71 \%$ of total running time $(8 \mathrm{~h})$.

Fig. 5 shows the performance of System B3 at sunny weather. It is seen that the solar PV $(900 \mathrm{Wp})$ generates power higher than the load power at high solar radiation periods. The battery charge/ discharge curve shows that, the battery is always discharged enough energy to the load, mostly at early morning and late afternoon. The runtime fraction $R_{F}$ of System B3 tested on March 4 , 2013 , is 0.992 . That is, the air conditioner is almost run $100 \%$ with

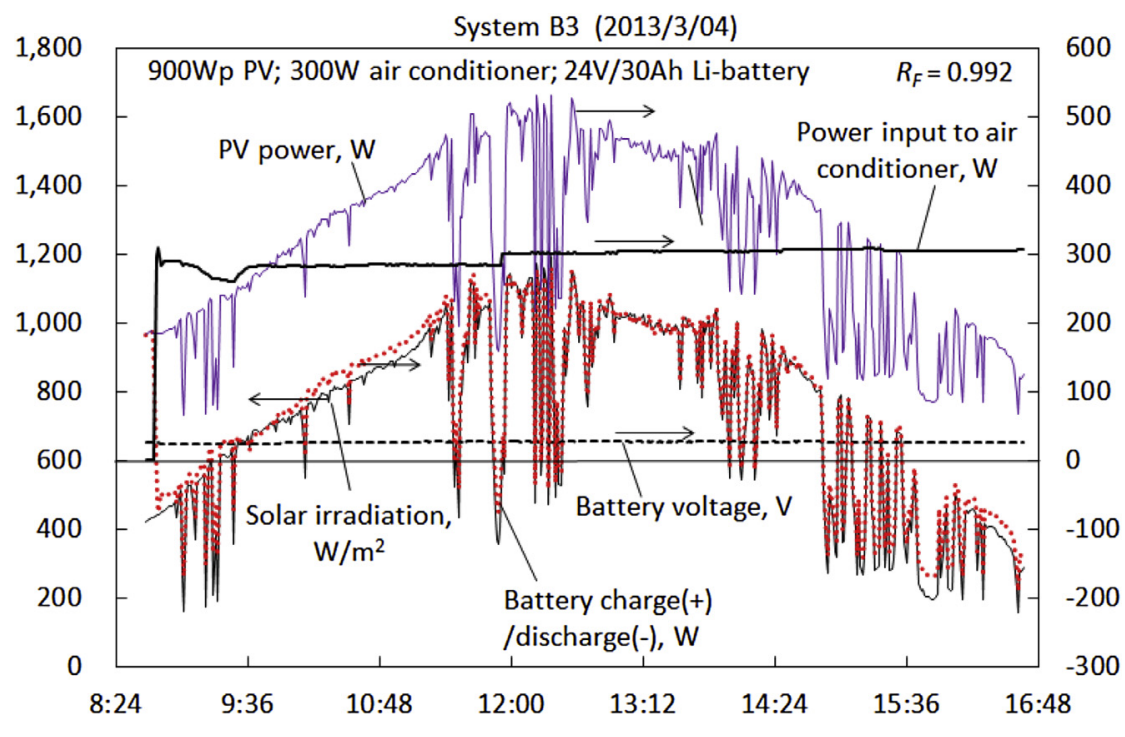

Fig. 5. Instantaneous operation of system B3 $\left(r_{p L}=3.0\right)$. 


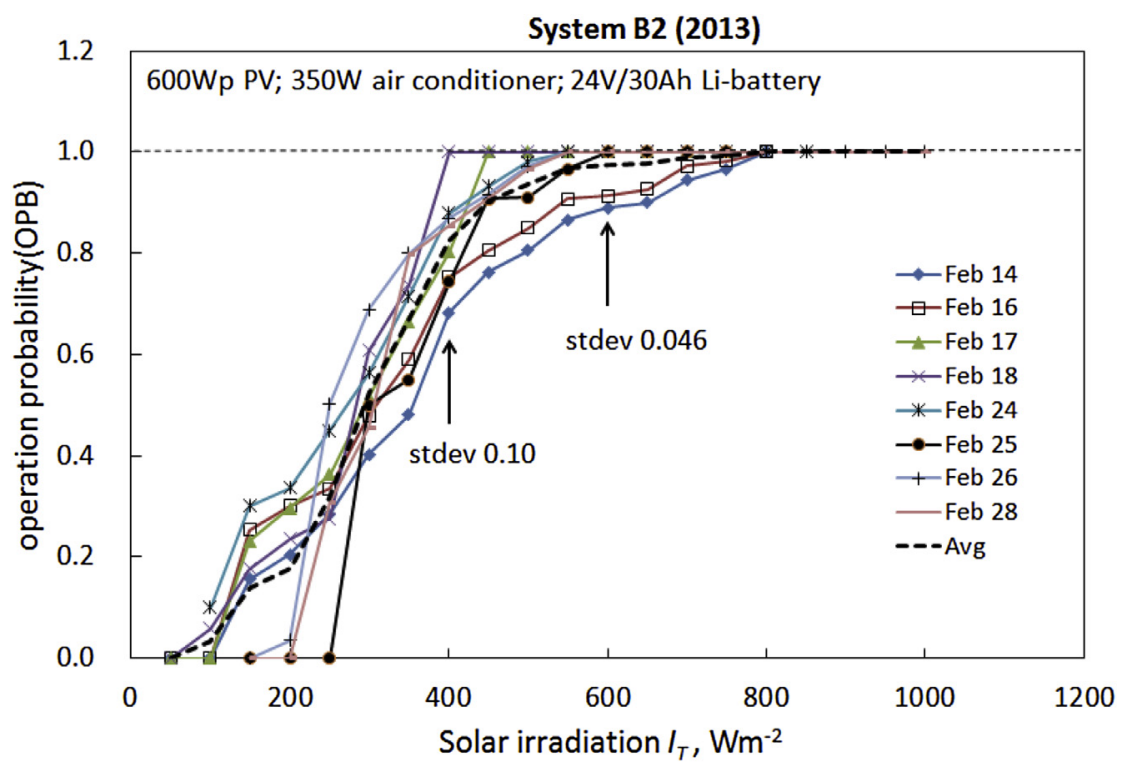

Fig. 6. Operation probability (OPB) of system B2.

solar power all the day.

The instantaneous performance shows that the buffer battery plays an important role in stabilizing the air conditioning system operation, especially under fast variation of solar irradiation. It is also seen that a larger PV size will increase the runtime fraction $R_{F}$ of the solar air conditioner.

\subsection{Daily-total performance statistics}

It is seen from Figure 3 to Figure 5 that, the factor influencing load power loss or runtime fraction $\left(R_{F}\right)$ is quite complicated. It is related to the design of PV system (PV module size, battery capacity), the variation of solar irradiation, the profile of load power etc.

The operation probability $(O P B)$ of solar air conditioner defined in eq. (1) can be used to evaluate the running probability at given solar irradiation. Fig. 6 is the OPB test results of System B2 at various weather conditions. It is seen that the solar irradiation for $100 \%$ OPB may vary in a wide range, from 400 to $800 \mathrm{Wm}^{-2}$. OPB reaches 1.0 at solar irradiation $I_{T}>800 \mathrm{Wm}^{-2}$ for all test conditions. Since the OPB appears randomly, we define a statistical average curve (dotted line in Fig. 6) to represent the most probable performance, with standard deviation (stdev) as shown in Fig. 6. Therefore, OPB of System B2 is $0.98 \pm 0.046$ at $I_{T}=600 \mathrm{Wm}^{-2}$ and $0.82 \pm 0.10$ at $I_{T}=400 \mathrm{Wm}^{-2}$.

The OPB tests were conducted for six systems in different time and the averaged OPB is shown in Fig. 7. It is found that the average OPB curves of System A1, A2, and C almost coincide. It is interesting to note that $r_{p L}$ of System A1, A2, and C is almost identical (2.15 for System A1 and A2 and 2.12 for System C). The OPB of solar air conditioners is found closely related to $r_{p L}$. The test results show that OPB is greater than 0.98 at $I_{T}>600 \mathrm{~W} \mathrm{~m}^{-2}$ for system design with $r_{p L}>1.71$. The OPB curve tends to rise more quickly with increasing $I_{T}$ for system with larger $r_{p L}$. $r_{p L}$ of System B3 is the

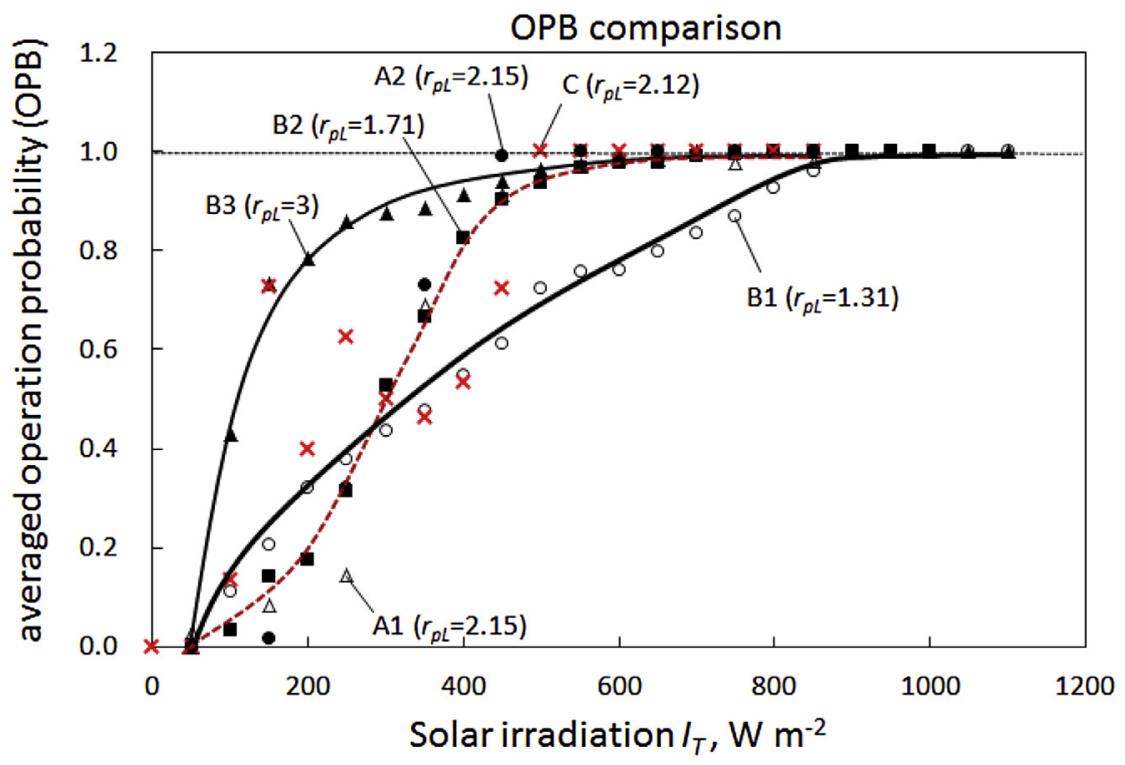

Fig. 7. Comparison of averaged operation probability (OPB). 


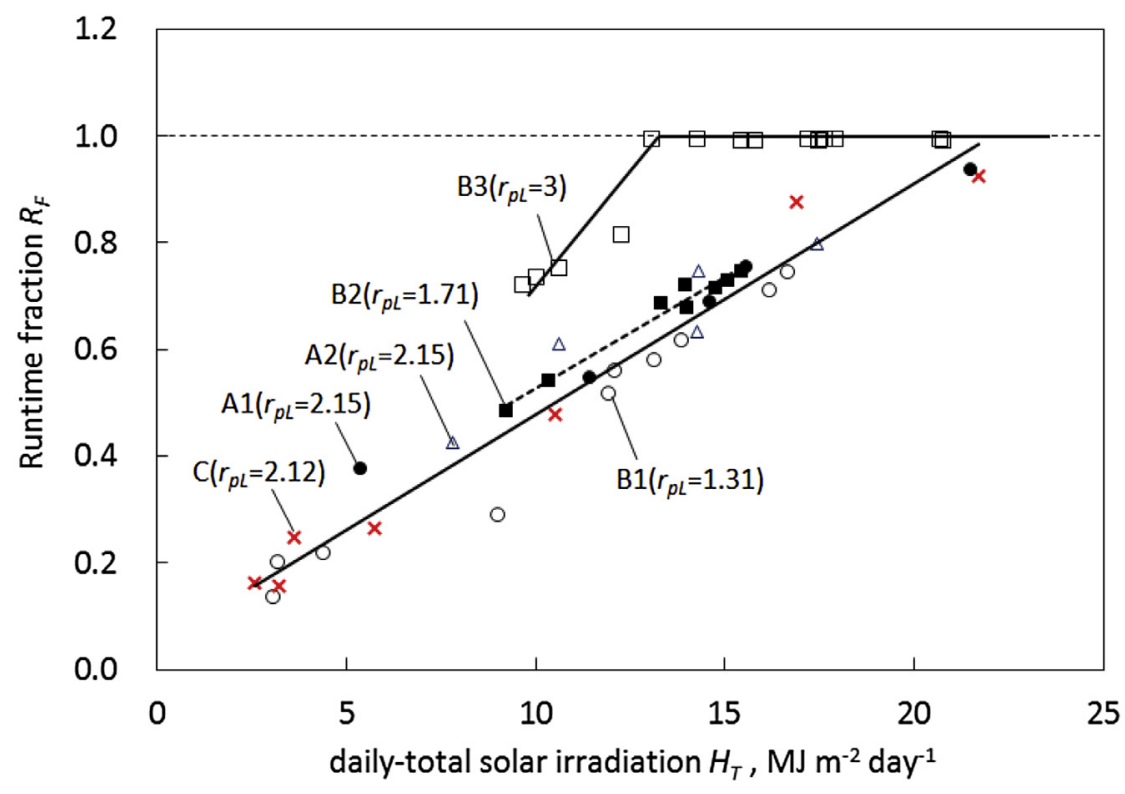

Fig. 8. Comparison of runtime fraction $\left(R_{F}\right)$.

highest (3.0) in all six systems tested. The OPB of System B3 reaches 0.80 at $I_{T}=200 \mathrm{~W} \mathrm{~m}^{-2}$ (cloudy). That is, the OPB will be very high if solar PV module installed is three times of load power $\left(r_{p L}=3\right)$.

All the test results of six systems at different time are used to calculate the runtime fraction $R_{F}$ at different weather conditions. Fig. 8 shows that, for all six systems except System B3, $R_{F}$ reaches 1.0 only in very sunny days at $H_{T}>22 \mathrm{MJ} \mathrm{m}^{-2}$ day $^{-1}$. However, for System B3, $R_{F}$ reaches 1.0 at $H_{T}>13 \mathrm{MJ} \mathrm{m}^{-2}$ day $^{-1}$, partly cloudy. This is due to the high value of design parameter $r_{p L}(=3.0)$.

\section{Discussions}

\subsection{Key design parameter}

It is seen that from instantaneous operation results shown in Fig. 3 through 5, the PV system design (PV module size, battery capacity), the variation pattern of solar irradiation, and the load profile influence the operation probability (OPB) and runtime fraction $\left(R_{F}\right)$ of solar air conditioner. It is found from the field test results that the $R_{F}$ and OPB curves of System A1, A2, and C are almost identical. This is due to the fact that the design parameter $r_{p L}$ of System A1 and A2 are the same (2.15) and very close to System C (2.12). Apparently, $r_{p L}$ is the key parameter in the design of solar air conditioning system.

\subsection{Design for high $\mathrm{OPB}$ and $R_{F}$}

The field test result shows that OPB will be higher than 0.98 at $I_{T}>600 \mathrm{Wm}^{-2}$ if the design parameter $r_{p L}>1.71$. Only System B1 $\left(r_{p L}=1.31\right)$ cannot achieve this.

For daily-total performance, $R_{F}$ is approximately 1.0 at dailytotal solar radiation $H_{T}>13 \mathrm{MJ} \mathrm{m}^{-2} \mathrm{day}^{-1}$ (partly cloudy), if $r_{p L}>3$. Only System B3 can achieve this. From Fig. 7, the OPB reaches 0.8 at very low solar radiation $I_{T}=200 \mathrm{Wm}^{-2}$ (cloudy), if the solar PV module installed is three times of load power (System B3).

That is, $r_{p L}=3$ is a suitable design for high OPB and $R_{F}$.

No clear relationship of $R_{F}$ and OPB with $t_{b p}$ and $t_{b L}$ is found. $t_{b p}$ ranges from $0.42 \mathrm{~h}$ to $1.1 \mathrm{~h}$ and $t_{b L}$ ranges from $0.89 \mathrm{~h}$ to $2.18 \mathrm{~h}$, for all six systems tested. The minimum $t_{b p}$ is $0.42 \mathrm{~h}$ and the minimum $t_{b L}$ is $0.89 \mathrm{~h}$.
Actually, OPB and $R_{F}$ is affected by variation pattern of solar radiation, which is dependent of local climate. The field test was performed outdoor in Taipei, in subtropical zone. The present conclusion may be only valid for subtropical climate.

\subsection{Direct solar-driven air conditioner applied in electric vehicle}

Solar air conditioning system developed in the present study is based on the concept of direct solar driven. Battery acts only as buffer energy storage for balance of solar and load power, and smooth operation of compressor under variable solar radiation. If the present solar air conditioner design is applied to electric vehicles, energy consumption, weight, space, and cost of solar PV system need to be considered. The design to reach high OPB and $R_{F}$ will be the major concern in electric vehicle. Hence, the design with $r_{p L}=2$ for $\mathrm{OPB}=0.8$ at solar irradiation $I_{T}=400 \mathrm{Wm}^{-2}$ may be proper. For the design with $r_{p L}=3$, i.e. PV module installed is three times of load power, $R_{F}$ is 1.0 at $H_{T}=13 \mathrm{MJ} \mathrm{m}^{-2}$ day $^{-1}$ (partly cloudy). The air conditioner is almost $100 \%$ powered by solar PV in partly-cloudy weather. This design will also provide excess solar power for charging the main battery of electric vehicle at solar irradiation $H_{T}>13 \mathrm{MJ} \mathrm{m}^{-2}$ day $^{-1}$.

Since $R_{F}$ is related to solar fraction, $1-R_{F}$ represents the ratio of energy supply from other energy source, for example, the power battery of electric vehicle. The design with $r_{p L}$ between 2.0 and 3.0 may be reasonable for electric vehicle. Besides, the estimation of $R_{F}$ and OPB for electric vehicle using the present results may be conservative since power consumption of air conditioner is proportional to solar radiation intensity. The measured $R_{F}$ and OPB of the six systems in the present study are all under constant power consumption of air conditioner in the field test. Actually, power consumption of air conditioner in electric vehicle will be decreased with decreasing solar radiation. Therefore, practical OPB and $R_{F}$ in electric vehicle will be higher than the present results.

\subsection{Future work}

The operation probability (OPB) and runtime fraction $R_{F}$ of solar air conditioner represents the risk of power loss in a stand-alone solar system. Lower risk may require higher investment on larger 
solar system and battery storage. There exists an optimization which needs further studies.

The solar air conditioners tested in the present study uses small buffer battery and no MPPT, the cost and the energy loss may be lower. However, it needs more investigations to find optimal design to achieve low system cost and lower risk of power loss.

\section{Conclusion}

The design of direct solar PV driven air conditioner based on stand-alone solar PV system is studied. The air conditioner is driven directly by solar PV module through an inverter. No grid power is connected. In order to balance the solar PV power and load power and reduce the cost, a small buffer battery is installed. Hence, the air conditioner may suffer from loss of power which can be characterized by two variables, instantaneous operation probability (OPB) and daily overall runtime fraction $\left(R_{F}\right)$

In order to study the effect of system design parameters on $O P B$ and $R_{F}$, six solar air conditioners were designed and built in the present study. It is seen from test results that, the major factor influencing OPB and $R_{F}$ is the design parameter $r_{p L}$ (ratio of maximum PV power to load power).

The test results show that OPB is greater than 0.98 at instantaneous solar irradiation $I_{T}>600 \mathrm{~W} \mathrm{~m}^{-2}$ for system design with $r_{p L}>1.71$. The OPB curve tends to rise more quickly with increasing $I_{T}$ for system with larger $r_{p L}$.

The OPB B3 reaches 0.80 at $I_{T}=200 \mathrm{~W} \mathrm{~m}^{-2}$ (cloudy) for the design with $r_{p L}=3$ (i.e. solar PV module installed is three times of load power).

For daily-total performance, $R_{F}$ is approximately 1.0 at dailytotal solar radiation $H_{T}>13 \mathrm{MJ} \mathrm{m}^{-2}$ day $^{-1}$ (partly cloudy), for $r_{p L}>3$. That is, $r_{p L}=3$ is a suitable design for high OPB and $R_{F}$.

No clear relationship of $R_{F}$ and OPB with $t_{b p}$ and $t_{b L}$ is found. But, $t_{b p}$ ranges from $0.42 \mathrm{~h}$ to $1.1 \mathrm{~h}$ and $t_{b L}$ ranges from $0.89 \mathrm{~h}$ to $2.18 \mathrm{~h}$, for all six systems tested. That is, the minimum $t_{b p}$ is $0.42 \mathrm{~h}$ and the minimum $t_{b L}$ is $0.89 \mathrm{~h}$.

\section{Acknowledgment}

This study was supported by National Energy Program II, MOST 103-3113-E-002-006 made by Ministry of Science and Technology, Taiwan, and by Award No.KUK-C1-014-12, made by King Abdullah University of Science and Technology (KAUST), Saudi Arabia.

\section{Nomenclatures}

$E_{\text {bato }}$ rated capacity of battery, Wh

$E_{\text {bat }} \quad$ usable energy storage capacity of battery, Wh (= $\left.D O D \times E_{\text {bato }}\right)$

$D O D$ depth of discharge of battery

$H_{T} \quad$ daily-total solar irradiation on PV surface, $\mathrm{MJ} \mathrm{m}{ }^{-2} \mathrm{day}^{-1}$

$I_{T} \quad$ instantaneous solar irradiation on PV surface, $\mathrm{W} \mathrm{m}^{-2}$

$\triangle I_{T} \quad$ radiation increment to calculate OPB, chosen as $50 \mathrm{~W} \mathrm{~m}^{-2}$

$O P B \quad$ operation probability of air conditioner, defined in eq. (1)

$R_{F} \quad$ runtime fraction (ratio of total running time of air conditioner to total service time), defined in eq. (2) $r_{p L} \quad$ ratio of maximum PV power generation to load power.

$t_{b L} \quad$ time to fully charge the battery at maximum PV power generation, $h$

$t_{b p} \quad$ time to fully charge the battery at maximum PV power generation, $\mathrm{h}$

$t_{O N} \quad$ total running time of air conditioner, $\mathrm{h}$

$t_{\text {total }} \quad$ total service time, $\mathrm{h}$ (chosen as $8 \mathrm{~h}$ )

$\triangle t_{o n, \mathrm{j}} \quad$ time segment while the air conditioner is running at given solar radiation $\mathrm{I}_{\mathrm{Tj}} \pm \triangle I_{T}$, $\mathrm{h}$

$\triangle t_{I T} \quad$ time of occurrence of $I_{T j} \pm \triangle I_{T}, \mathrm{~h}$

$W_{L} \quad$ load power, $\mathrm{W}$

$W_{p v} \quad$ rated PV maximum power generation, $\mathrm{W}_{\mathrm{p}}$

\section{References}

[1] P.J. Axaopoulos, M.P. Theodoridis, Design and experimental performance of a PV ice-maker without battery, Sol. Energy 83 (2009) 1360-1369. http://doi: 10.1016/j.solener.2009.03.007.

[2] F.J. Cabrera, A. Fernández-García, R.M.P. Silva, M. Pérez-García, Use of parabolic trough solar collectors for solar refrigeration and air-conditioning applications, Renew. Sust. Energy Rev. 20 (2013) 103-118.

[3] O.M.M. El Tom, S.A. Omer, A.Z. Taha, A.A.M. Sayigh, Performance of a photovoltaic solar refrigerator in tropical climate conditions, Renew. Energy 1 (1991) 199-205.

[4] N. Hartmann, C. Glueck, F.P. Schmidt, Solar cooling for small office buildings: comparison of solar thermal and photovoltaic options for two different European climates, Renew. Energy 36 (5) (2011) 1329-1338.

[5] H.M. Henning, Solar assisted air conditioning of buildings - an overview, Appl. Therm. Eng. 27 (10) (2007) 1734-1749.

[6] B.J. Huang, F.S. Sun, R.W. Ho, Near-maximum-power-point-operation design of photovoltaic power generation system, Sol. Energy 80 (8) (2006) 1003-1020.

[7] B.J. Huang, P.C. Hsu, M.S. Wu, P.Y. Ho, System dynamic model and charging control of lead-acid battery for stand-alone solar PV system, Sol. Energy 84 (2010) 822-830.

[8] B.J. Huang, R.H. Yen, T.F. Hou, S.W. Chang, T.L. Lin, R.H. Liu, Y.C. Lin, K.R. Lin, Y.H. Chuang, Hsu, Agun, L.T. Wu, C.T. Liu, J.F. Yeh, Design of a zero-energy house utilizing advanced material and technology, in: Proceedings of the International Conference on Engineering Solutions for Sustainable Development, American University in Cairo, Cairo, Egypt, April 17-18, 2010.

[9] B.J. Huang, J.H. Wu, R.H. Yen, J.H. Wang, H.Y. Hsu, C.J. Hsia, C.W. Yen, J.M. Chang, System performance and economic analysis of solar-assisted cooling/heating system, Sol. Energy 85 (11) (2011) 2802-2810.

[10] B.J. Huang, T.F. Hou, Y.H. Chuang, T.L. Lin, K.R. Lin, Y.H. Yeh, P.C. Hsu, M.Y. Yeh, Y.Y. Hsieh, C.T. Liu, J.F. Yeh, L.T. Wu, P.L. Chong, J.C. Wang, R.H. Yen, Development of zero-energy house in NTU, in: The 4th Energy and Environmental Workshop. AEARU EEW 2012. March 29-30, 2012, Taipei, Taiwan, 2012.

[11] B.J. Huang, W.Z. Ton, C.C. Wu, H.W. Ko, H.S. Chang, H.Y. Hsu, J.H. Liu, J.H. Wu, R.H. Yen, Performance test of solar-assisted ejector cooling system, Int. J. Refrig. 39 (2014) 172-185. http://dx.doi.org/10.1016/j.ijrefrig.2013.06.009.

[12] B.J. Huang. T.H. Lin, YT. Chen, P.C. Hsu, K. Lim, Solar PV-driven air conditioner, in: EuroSun 2014 (Ed.), International Conference on Solar Energy and Buildings. September 16-19, 2014. Aix-les-Bains, France, 2014.

[13] S. Kaplanis, S. Papanastasiou, The study and performance of a modified conventional refrigerator to serve as a PV powered one, Renew. Energy 31 (2006) $771-780$.

[14] T.A. Kattakayam, K. Srinivasan, Uninterrupted power supply for autonomous small refrigerators, Energy Convers. Manag. 39 (1998) 21-26.

[15] T.A. Kattakayam, K. Srinivasan, Thermal performance characterization of a photovoltaic driven domestic refrigerator, Int. J. Refrig. 23 (2000) 190-196.

[16] R.M. Lazzarin, Solar cooling: PV or thermal? A thermodynamic and economical analysis, Int. J. Refrig. 39 (2014) 38-47.

[17] A.Z. Taha, The oversizing method of estimation in PV systems, Renew. Energy 6 (1995) 487-490

[18] S. Toure, W.F. Fassinou, Cold storage and autonomy in a three compartments photovoltaic solar refrigerator: experimental and thermodynamic study, Renew. Energy 17 (1999) 587-602. 